\title{
AGRESSIVIDADE E ESCOLA: PROJETO DE INTERVENÇÃO PROTAGONIZADO POR PROFESSORES
}

\author{
A. C. S. WIEZZEL \\ Universidade Estadual Paulista - Faculdade de Ciências e Tecnologia \\ ORCID ID: http://orcid.org/0000-0003-4592-5421 \\ www.fct.unesp.br
}

Submetido em 31/08/2017 - Aceito em 16/08/2020

DOI: $10.15628 /$ holos. 2020.6260

\section{RESUMO}

O artigo trata de uma pesquisa-ação, realizada com 36 professores de escolas públicas de um município do interior de São Paulo-SP, com o objetivo de construir projetos que pudessem sanar problema relativo à manifestações agressivas em sala de aula. Utilizou-se, como instrumentos de coleta de dados, relatos, questionários, materiais produzidos em salas de aula (relatórios, portfólios, atividades realizadas pelas crianças) e fotos. Após a realização de trabalho técnico a respeito da agressividade infantil envolvendo a pesquisadora e os professores, os últimos planejaram os projetos, os desenvolveram em salas de aula e avaliaram seus impactos às relações interpessoais das crianças envolvidas. Os resultados apontaram participação ativa dos professores em todo o processo da pesquisa, ocorrendo transformações significativas no cotidiano das salas de aula no que se refere às interações entre as crianças.

PALAVRAS-CHAVE: agressividade, intervenção, professores, educação infantil.

\section{AGGRESSIVENESS AND SCHOOL: INTERVENTION PROJECT LED BY TEACHERS}

\begin{abstract}
The article is about an action research, carried out with 36 teachers from a town of the state São Paulo-SP, that aimed building projects that could solve a problem related to aggressive manifestations in the classroom. Reports, questionnaires, materials that were produced in classrooms (reports, portfolios, activities performed by children) and photos were used as data collection instruments. After carrying out technical work related to
\end{abstract}

child aggressiveness involving the researcher and teachers, the ladder planned the projects, developed them in classrooms and assessed their impacts on the interpersonal relationships of the children involved. The results showed active participation of teachers throughout the research process, with significant transformations identified in everyday life in the classrooms with regard to interactions between children.

KEYWORDS: aggressiveness, intervention, teachers, child education. 


\section{INTRODUÇÃO}

É preciso ter esperança, mas ter esperança do verbo esperançar; porque tem gente que tem esperança do verbo esperar.

E esperança do verbo esperar não é esperança, é espera. Esperançar é se levantar, esperançar é ir atrás, esperançar é construir, esperançar é não desistir! Esperançar é levar adiante, esperançar é juntar-se com outros para fazer de outro modo. (Paulo Freire)

A agressividade constitui um grande desafio às famílias e instituições escolares na educação de crianças em nível mundial. Este inquietante componente do desenvolvimento emocional tem motivado inúmeros debates e pesquisas, considerando-se os possíveis prejuízos materiais e humanos que pode causar. Conforme Pervova (1999) vários indicadores - dentre eles os da ONU (Organização das Nações Unidas) e BID (Banco Interamericano de Desenvolvimento) - demonstram crescentes percentuais de perdas nas escolas, oriundas da delinquência, porte de armas, drogadição, ameaças, violência sexual, discriminação e outros.

Tais prejuízos têm mobilizado os pesquisadores a uma intensa busca de compreensão do fenômeno. No Brasil, em levantamento realizado junto às bases de dados SciELO, LILACS, INDEX PSI, Biblioteca Digital da USP, Biblioteca Virtual da Unicamp, BIREME e Athen@, foram localizados cerca de 11.200 trabalhos que abordam a questão da agressividade, nos mais diversos âmbitos. Neste conjunto, estabelecendo como parâmetro a área da educação, se sobressaem pesquisas relacionadas ao bullying, às representações dos professores acerca da agressividade e caracterização de comportamentos agressivos entre alunos do ensino fundamental e ensino médio.

Com relação à educação infantil - a faixa etária de interesse neste trabalho - foram localizadas 11 pesquisas, que analisaram a agressividade predominantemente na linha da psicologia cognitivo-comportamental. Dentre os temas abordados destacam-se as concepções e práticas dos professores, o sofrimento dos professores no trabalho com as crianças com agressividade e caracterizações comportamentais de agressividade em sala de aula. Dentre os principais resultados apresentados por esses estudos destacam-se a preocupação, o desgaste físico/emocional e desorientação dos professores com relação à temática, bem como a prevalência de muita agressividade física entre as crianças.

Embora os resultados das pesquisas apontem a desorientação dos professores, não se observam investigações que, além de compreender e caracterizar a agressividade na escola de educação infantil, desenvolvam estratégias ou práticas que sejam relevantes aos professores quanto ao desenvolvimento social das crianças. Pensando nesta carência bibliográfica, na angústia, dificuldades e necessidades formativas dos professores, iniciou-se um amplo projeto de pesquisa, entre os anos 2008 e 2016. Na primeira etapa o intuito foi de compreender, do ponto de vista teórico, as origens, os processos e as características da agressividade no ser humano. Na segunda etapa, a pesquisa envolveu trabalho de campo com crianças entre quatro e seis anos, com o objetivo de investigar os fatores endógenos e exógenos que influenciavam em suas manifestações agressivas em sala de aula. 
Nesta etapa, da qual participaram 52 crianças, concluiu-se que a agressividade está relacionada a uma complexa e dinâmica rede de relações e experiências, que desestabilizam o desenvolvimento emocional, prejudicando as interações sociais das crianças. Tais resultados estruturaram a execução da terceira etapa da pesquisa, realizada em 2016, e sobre a qual tratará este artigo. Esta etapa teve por objetivo auxiliar professores de escolas de educação infantil na elaboração, execução e avaliação de projetos de trabalho envolvendo a agressividade infantil. Como objetivos específicos, buscou-se proporcionar aos professores um espaço em que pudessem externalizar seus sentimentos e dificuldades com a agressividade; apresentar a eles dados importantes à reflexão acerca da agressividade; sensibilizá-los com relação às crianças, isto é, mostrar o que acontece com elas, porque reagem de tal forma e discutir, junto ao grupo, possíveis formas de trabalho com as crianças.

\section{A AGRESSIVIDADE NA TEORIA DE WINNICOTT}

Há algumas vertentes na Psicologia que, para explicar a questão da agressividade, a localiza ou no plano dos fatores exógenos ou no plano dos fatores endógenos. No ponto de vista da psicanálise infantil, encontra-se uma abordagem que considera tanto a prevalência de fatores exógenos quanto endógenos quando se trata de discutir a agressividade. Esta abordagem é defendida por autores como Winnicott, que busca compreender a agressividade em uma perspectiva mais ampla e aponta a possibilidade do lúdico como alternativa de trabalho com as crianças afetadas por esta dificuldade.

Donald Woods Winnicott (1896-1971) biólogo, pediatra, psiquiatra e psicanalista infantil teve seus primeiros contatos com o tema agressividade na coordenação de uma instituição, na Inglaterra, que recebia crianças e adolescentes em situação de risco, consideradas "difíceis". Com a Segunda Guerra Mundial, foi nomeado Psiquiatra Consultor do Plano de Evacuação Governamental, se deparando com o desafio de cuidar e tratar dessas crianças, já que suas condições comportamentais não permitiam que fossem inseridas nos lares comuns, ainda mais no contexto de uma guerra. As análises de Winnicott o levaram a supor que as crianças sofriam devido a privações ocorridas nos anos iniciais de vida, que ressoavam na adolescência ou mesmo no meio da própria infância (Winnicott, 2005).

Rapidamente, Winnicott passou ao estudo das pulsões, distúrbios de caráter e manifestações da tendência antissocial, considerando não apenas a interferência dos conflitos inconscientes mas dos fatores ambientais, analisando as histórias de vida dos sujeitos. Além de Winnicott, outro psicanalista infantil chamado John Bowlby, também realizou estudos dos antecedentes de crianças encaminhadas ao seu instituto, concluindo, a partir de 150 casos, que o roubo estava associado à privação das crianças de contato com suas mães nos primeiros anos de vida.

Winnicott $(1982,2005)$ localiza os impulsos agressivos no ser humano ainda no ventre, cuja existência pode ser exemplificada pelos "chutes" na barriga da mãe, sem a intenção de ferir. Destaca que a agressividade é inerente ao ser humano e é particularmente relevante ao seu processo 
adaptativo, porém, adverte que a capacidade da criança em lidar com a agressividade, de maneira a usá-la apropriadamente, envolve longo caminho. A agressividade, naturalmente, é expressa de alguma maneira: bebês mordem o seio da mãe, crianças pequenas machucam fisicamente outras na escola, crianças deixam os pais exaustos com sua excitação ou pedido de "limites". O que importa é que inicialmente e, ao contrário da violência, essas manifestações não têm a intenção de machucar, já que decorrem de processos constituintes do desenvolvimento emocional infantil, sobretudo nos primeiros anos de vida.

Diante disso, Winnicott (1982) aponta a importância de um ambiente acolhedor, que trabalhe a expressão dos impulsos agressivos já no início da escolarização, sem que as crianças percam a espontaneidade e a capacidade de usar a agressividade nos momentos de proteção. Quando a criança não é devidamente cuidada ou não dispõe de um ambiente facilitador no início da vida, a agressividade tem como motivação um medo de perda do controle ou, então, é utilizada como forma de teatralizar a insegurança interna, em ambos os casos funcionando como um pedido de socorro ao mundo externo. Quando não bem resolvida a agressividade passa a ser utilizada a serviço do ódio, podendo ocasionar tanto a tendência antissocial como a delinquência (Winnicott, 2005).

Como as crianças permanecem por muitas horas na escola e, principalmente, por terem esperança de serem auxiliadas por seus professores, é comum o envolvimento em brigas e discussões, a prática de atos desrespeitosos com os outros alunos, com o próprio professor etc. 0 que a criança busca com essas manifestações é uma contenção por parte do ambiente, algo que necessita para, progressivamente, ir lidando de forma mais organizada com sua agressividade (Winnicott, 2005).

Dentre os motivos que podem levar a criança a manifestar agressividade em nível preocupante, o principal deles, para Winnicott $(1982,1992,2005)$, reside na privação do contato materno nos primeiros anos de vida. Quando a criança passa por sucessivas experiências de ausência materna ou quando estas excedem a capacidade da criança em manter viva, em sua lembrança, as experiências boas que teve com essa pessoa, cria-se um campo de angústia impensável ${ }^{1}$, que pode causar uma instabilidade no desenvolvimento emocional. Diante da desregulação no desenvolvimento não é possível o desabrochar de algumas características afetivas importantes para que o sujeito consiga empregar a agressividade como forma de defesa e de adaptação ao mundo, sem direciona-la de forma inadequada ou desnecessária às pessoas.

Associados a esse fator principal, podem ser encontrados na criança que manifesta agressividade conflitos emocionais de origens diversas, experiências traumáticas isoladas, ocorrências que trouxeram sofrimento, dúvidas e interpretações distorcidas da realidade, falta de continência à agressividade, experiências negativas decorrentes de fatores sociais e econômicos, bem como episódios de rejeição vividos na escola e/ou no lar, sejam estes reais ou fantasiosos. Temse, por um lado, um contexto saudável de desenvolvimento infantil interrompido e, por outro,

\footnotetext{
${ }^{1}$ Termo utilizado por Winnicott na obra Privação e delinquência.
} 
agravantes situações de vida.

Para Winnicott (1982), portanto, os bons cuidados que a criança recebe ao nascer - seja pela mãe ou alguém que se responsabilize por ela - seria o princípio mais importante a ser considerado na perspectiva de um saudável desenvolvimento emocional. Esclarece, em todas as suas obras, que a criança depende de relações afetivas estáveis e contínuas com a família, principalmente nos dois primeiros anos de vida, para que adquira segurança. Aponta que, na ausência deste tipo de relação, a criança pode não conseguir alcançar uma organização interna madura, capaz de suportar sentimentos destrutivos e angústias que fazem parte de seu desenvolvimento emocional.

Para Winnicott (2005), a agressividade seria utilizada, inconscientemente, como forma de a criança obter ajuda externa para uma reorganização interna. Busca, por meio desta ajuda, recuperar um ambiente propício à retomada do desenvolvimento emocional saudável, restabelecendo a segurança psíquica que, por algum motivo, fragilizou-se. Ainda conforme o autor a criança, na tentativa de reparar aquilo que julga ter perdido, passa a incomodar o ambiente na esperança de que o professor - a quem julga se importar com ela - a ajude a lidar com emoções extremamente fortes para seu ego ainda em formação.

Diante disso Winnicott (1982) destaca a relevância de os professores estarem atentos e sensíveis às crianças, de forma a perceberem suas necessidades individuais de desenvolvimento e oferecerem apoio especializado. As crianças que manifestam agressividade precisam de um relacionamento acolhedor, com base no respeito e autoridade do professor em seus ataques de fúria. No plano mais geral, fora deste âmbito em que a criança necessita de intervenção individualizada, é possível, a partir dos conhecimentos etiológicos a respeito da agressividade, propor projetos de trabalho que envolvam todos os alunos da sala de aula, de forma a incluir a criança que está agressiva, pois, geralmente, ela se isola ou é isolada pelas demais, por medo.

Nesta perspectiva esta pesquisa surge como forma de enfrentamento à agressividade, pautando-se em um trabalho especializado, consciente, coletivo e transformador, que possa estruturar a prática educativa e oferecer aos professores o referencial necessário para refletir sobre o problema. A seguir será apresentada a trajetória de um grupo de professores que aceitou o desafio de trabalhar a agressividade por meio de projetos de atividades, em escolas de educação infantil, na condição de pesquisadores de sua própria prática.

\section{METODOLOGIA}

O trabalho foi desenvolvido por meio da pesquisa-ação, que visa sanar determinada questão ou problema de forma coletiva. Para Thiollent (2005):

é um tipo de pesquisa social com base empírica que é concebida e realizada em estreita associação com uma ação ou com a resolução de um problema coletivo e no qual os pesquisadores e os participantes representativos da situação ou problema estão envolvidos de modo cooperativo ou participativo. (Thiollent, 2005, p. 16) 
Participaram da pesquisa 36 professores de escolas de educação infantil de um município do interior de São Paulo-SP. Além dos professores, integraram a equipe a Secretária de Educação do município e uma aluna bolsista de iniciação científica do Curso de Pedagogia. O trabalho foi desenvolvido por meio de reuniões mensais, na Secretaria de Educação. A primeira reunião teve como objetivo a coleta de dados, utilizando-se como instrumentos um questionário e relatos de experiência. A segunda e a terceira reunião foram reservadas para o desenvolvimento de um trabalho teórico com os professores - envolvendo a teoria de Winnicott - e discussão de atividades pedagógicas e formas de interação com as crianças com agressividade. Para a quarta reunião, a programação envolveu a elaboração, pelos professores, dos projetos de atividades que seriam desenvolvidos em salas de aula, com as crianças, por um período de 30 dias. A quinta e última reunião contemplou o compartilhamento das experiências dos professores na execução dos projetos, as atividades produzidas, os resultados obtidos e as avaliações sobre o trabalho. A pesquisadora e a aluna bolsista utilizaram diários de bordo em todas as reuniões para o registro dos dados mais significativos. Tais dados, assim como aqueles obtidos nos questionários preenchidos pelos professores no início e ao final do processo, foram analisados com base na teoria winnicottiana e na Análise de conteúdo, de Bardin (2006). Também foi realizado cotejamento entre os resultados obtidos e os objetivos da pesquisa, momento em que foi possível comparar as concepções e práticas dos professores com relação à agressividade no início e ao final da pesquisa.

\section{O DESENVOLVIMENTO DA PESQUISA E SEUS RESULTADOS}

Nesta seção será relatado o desenvolvimento da pesquisa e apresentados alguns resultados gerais obtidos no processo. Como as reuniões com os professores foram centrais no desenvolvimento da pesquisa, optou-se por descrevê-las e, simultaneamente, ir discutindo os dados obtidos em cada uma. A primeira reunião fora iniciada com a apresentação do projeto e da teoria que embasaria o trabalho. Após o esclarecimento de dúvidas, os 36 professores assinaram o Termo de Consentimento Livre e Esclarecido. A seguir, passou-se à coleta de dados sobre as experiências dos professores com relação à agressividade. Os instrumentos utilizados foram questionário e relatos, cujos dados, organizados por categorias, são apresentados na tabela 1.

Tabela 1: Dados acerca das experiências dos professores com relação à agressividade

\section{Categorias \\ Respostas \\ Frequência}

Porcentagem

(\%)

Percepção dos professores

sobre estarem ou não em

Sim

20

55,6

contato (em 2016) com crianças

com muita agressividade em sala de aula
Não
44,4 
Agressões físicas à colegas de sala e aos professores (socos,

pontapés, tapas no rosto)

Tipos de agressividade observadas pelos professores, entre as crianças, durante as aulas
Xingamentos

9

Agressões físicas à colegas de sala (socos, pontapés, empurrões, tapas no rosto e pernas)

Apreensão (causada por dúvidas sobre como proceder com as crianças)

Sentimentos dos professores em momentos nos quais Tristeza

presenciavam manifestações agressivas das crianças

Compaixão (necessidade de ajudar as crianças)

Falta de envolvimento da família com a escola; mudanças estruturais nas famílias; falta de

imposição de limites às crianças pelas famílias

Professores agressivos com as crianças; falta de suporte ao

Causas atribuídas pelos professores à agressividade das crianças professor (formação inicial e continuada)

Influência de mudanças culturais quanto aos objetivos da educação escolar

Realidade socioeconômica das famílias 
Percepção dos professores quanto a haver ou não um

aumento do número de

crianças com muita

agressividade, na educação

infantil, nos últimos anos

Não

0

0

Tendo em conta este levantamento geral, percebeu-se que entre os 36 professores participantes, 20 deles estavam trabalhando com crianças cujas manifestações agressivas se apresentavam de forma excessiva em sala de aula. Os tipos de manifestações agressivas entre essas crianças se mostraram incomuns para a faixa etária, caracterizando-se por agressões a professores e colegas por meio de xingamentos, tapas, socos, pontapés. O objetivo das crianças em tais condutas, conforme já explicitado anteriormente, diz respeito a um pedido de ajuda ao professor, de contenção, enfim, de acolhimento às suas necessidades emocionais (Winnicott, 2005).

Diante da situação predominava entre os professores um sentimento de apreensão, gerado pela seguinte dúvida: Como proceder com essas crianças? A identificação dessa necessidade formativa entre os docentes, evidencia a relevância desta pesquisa como forma de abrir caminhos a uma maneira alternativa de lidar com a agressividade infantil. Além da apreensão, os professores relataram tristeza, compaixão (expressa pela necessidade de ajudar as crianças) e preocupação, temendo o que poderia acontecer com elas no futuro. A apreensão, que remete à questão da dúvida apontada pelos professores, está claramente associada à formação acadêmica. As limitações na formação inicial e continuada são citadas pelos professores na questão seguinte, quando apontam as possíveis causas da agressividade na escola. Se há pouca produção acadêmica na área, isto se refletirá nos cursos de formação.

A respeito das outras possíveis causas que os professores atribuíram à agressividade, $61 \%$ da amostra (22 professores) indicou fatores inerentes ao ambiente familiar, tais como, "falta de envolvimento da família com a escola", "mudanças estruturais" na família (falta súbita de um dos pais), "falta de limites" (relacionada à educação familiar). No entanto, também foram apontados outros fatores, tais como "professores agressivos" (gritam com as crianças), "falta de suporte ao professor" (limitações na formação inicial e continuada e falta de auxílio por parte do coordenador pedagógico - já citado anteriormente), "influência de mudanças culturais" (a escola deve educar a criança integralmente; a agressividade como forma de resolução de conflitos) e "realidade socioeconômica" (grande vulnerabilidade econômica das famílias). A partir desses resultados, ficou claro à pesquisadora os aspectos a serem priorizados com esses profissionais no estudo teórico, de forma a articular todos os fatores que influenciavam na agressividade das crianças e refletir sobre possíveis soluções.

É importante reafirmar, de acordo com a teoria de Winnicott $(2000,2005)$, a existência de vários fatores que influenciam na agressividade e que esta é, na maior parte dos casos, originada por uma associação entre esses fatores. Para Winnicott (2005) as raízes da agressividade estão 
localizadas no próprio desenvolvimento humano e, para um bom desfecho, devem ser observadas as bases relacionais da criança, com as pessoas que cuidam dela em casa e na escola, já que é fundamental que ela tenha boas e estáveis relações nesses espaços. Outra justificativa para a agressividade da criança, ainda para Winnicott $(2000,2005)$, se dá a partir do que denomina agressividade episódica, caracterizada por crises que cessam após a resolução do conflito/fato que a causou. O professor, tendo conhecimento de toda essa dinâmica, terá melhores condições para compreender cada situação e analisar as possibilidades de trabalho. Conforme se observa na Tabela 1 há um reconhecimento, pelos professores, de que a agressividade tem se agravado nas escolas ao longo dos anos. Esse dado justifica novamente a preocupação deles com as crianças, já que se não houver uma intervenção o quadro agressivo pode evoluir e prejudicá-las em um futuro próximo. As experiências dos professores mostram exatamente isto.

Com bases nesses dados a próxima reunião (reunião 2) consistiu em trabalhar com os professores aspectos da concepção teórica de Winnicott $(1992,2005)$ que os auxiliassem na compreensão da agressividade e quanto à dúvida sobre como proceder com as crianças. O conteúdo apresentado pela pesquisadora aos professores nesta reunião, abordaram três grandes temas: 1Fatores que contribuem a um bom desenvolvimento emocional da criança; 2- Informações gerais sobre a agressividade (caracterização e origens) e 3- Ações por parte da escola e do professor para lidar com a agressividade. Uma síntese de todo esse conteúdo pode ser observada na Tabela 2.

Tabela 2: Síntese das discussões teóricas com os professores

TEMAS

Fatores que contribuem a um bom desenvolvimento emocional da criança

Informações gerais sobre a agressividade

\section{PONTOS DESTACADOS}

- bebê/criança pequena: precisa de cuidados, atenção e afeto contínuos por parte de quem cuida;

- importância de relações afetivas estáveis e contínuas no lar e escola.

- observa-se já no útero materno, a partir de pontapés do bebê na barriga da mãe (sem a intenção de ferir);

- mordidas do bebê no seio materno durante a amamentação por motivo de excitação (sem a intenção de ferir);

- ocorre em resposta à frustração em crianças;

- ocorre por imposições que a criança não aceita;

- pode ocorrer em qualquer lugar, por meio de explosões de raiva, gestos, agressões físicas e/ou verbais;

- evidencia pedido de auxílio onde a criança reconheça a existência de pessoas que se preocupem com ela; 
- pode ocorrer em resposta à dificuldades comuns ao desenvolvimento (exemplos: nascimento de irmão, conflitos com irmãos, mortes, dificuldade nas interações sociais, sentimentos de raiva e culpa, expectativas afetivas não realizadas, ter passado por experiências envolvendo agressividade, não saber comunicar verbalmente suas emoções);

- pode ocorrer diante de dificuldades inerentes aos relacionamentos na escola e/ou no lar;

- pode ocorrer por falta de segurança e confiabilidade nas pessoas;

- pode ocorrer por falta de continência (limites);

- pode ocorrer como forma de testar o ambiente e o amor das pessoas.

Ações da escola

- compreender as motivações para a agressividade;

- acolher a criança que precisa de auxílio: afeto, atenção, cuidado, continência;

- estabelecer relação de confiança com a família;

- troca de informações com a família;

- desenvolvimento de relações estáveis na escola;

- atividades pedagógicas envolvendo o brincar, brincadeiras e jogos que auxiliem no desenvolvimento emocional das crianças (atuam diretamente sobre os conflitos emocionais e as acalmam).

Após toda a apresentação teórica e discussão com a participação dos professores, foi lançado aos últimos o desafio de refletir sobre suas crianças, ressignificando as experiências que tiveram com elas, com base no conhecimento há pouco construído. Após o intervalo, alguns professores se dispuseram a falar sobre sua nova percepção acerca de algumas situações relatadas por eles na primeira reunião, assumindo uma postura menos persecutória ${ }^{2}$ e observando a situação com certo distanciamento, o que é imprescindível para uma tomada de decisão. Na sequência, os professores foram convidados a pensar sobre formas de atuação, por meio de atividades pedagógicas e relacionais ${ }^{3}$, que favorecessem as crianças. Neste contexto, indagou-se aos professores: "1- O que poderia ser feito, do ponto de vista relacional, para ajudar as crianças a

${ }_{2}^{2}$ Caracterizada pela crença de que o aluno realiza ações exclusivamente para provocar o professor.
${ }^{3}$ Refere-se à formas de interagir com as crianças, no âmbito da relação professor e aluno.

HOLOS, Ano 36, v.6, e6260, 2020 
lidarem com a agressividade? 2- Que tipos de atividades pedagógicas poderiam ser desenvolvidas com elas, de forma a trabalhar seus aspectos sociais?"

A partir deste momento foram apresentadas algumas sugestões de atividades para inspirar os professores na elaboração ou adaptação de atividades que trabalhassem direta ou indiretamente, as interações sociais. Dentre as atividades foram priorizadas as que envolviam o lúdico, pois, conforme apontam Aberastury (1992) e Winnicott (1975, 1982), o brincar atua sobre os estados emocionais das crianças, constituindo um canal para a expressão e elaboração de seus sentimentos.

Ao brincar, a criança desloca para o exterior seus medos, angústias e problemas internos, dominandoos por meio da ação. Repete no brinquedo todas as situações excessivas para seu ego fraco e isto the permite, devido ao domínio sobre os objetos externos a seu alcance, tornar ativo aquilo que sofreu passivamente, modificar um final que lhe foi penoso, tolerar papéis e situações que seriam proibidas na vida real tanto interna como externamente e também repetir à vontade situações prazerosas. (Aberastury, 1992, p. 15).

Para Winnicott $(1975,1982)$, assim como para Aberastury (1992) e Moyles (2006), o brincar constitui forma de a criança expressar como concebe o mundo e os fatos que estão à sua volta. Envolve uma dimensão que se situa em uma área intermediária entre o mundo real e a fantasia, permitindo à criança juntar aspectos desses dois mundos. É possível à criança, portanto, projetar suas fantasias e recria-las, resolver problemas, trabalhar com a flexibilidade e com as relações interpessoais, utilizando o brincar de acordo com suas necessidades momentâneas de desenvolvimento. Pelas características que assume, Winnicott (1982, p. 163) conclui: “a brincadeira fornece uma organização para a iniciação de relações emocionais e assim propicia o desenvolvimento de contatos sociais."

As atividades sugeridas aos professores eram simples, tais como: o Painel de sentimentos (atividade na qual as crianças reconhecem e classificam seus estados emocionais/sentimentos a partir de emojis); o brincar espontâneo - individualmente e em grupos - com a utilização de brinquedos comuns; a contação de histórias (a partir de enredos que envolvam questões emocionais importantes ao desenvolvimento infantil, como em "João e Maria", na qual se trabalha o medo da perda dos pais); músicas (cujos temas explorem a amizade, o amor, o cuidado); cantigas de roda; trabalhos com texturas, cores, sons, sabores; atividades que envolvam cuidados (as crianças se responsabilizam por cuidar de uma planta, animal ou boneco), dentre outras. Todas essas atividades fazem com que a criança entre em contato consigo mesma, possibilitando a expressão e reorganização interna de sentimentos. A intenção seria trabalhar o desenvolvimento emocional das crianças bem como incorporar o brincar às atividades corriqueiras das salas de aula, assim como preconiza Moyles (2006). Muitas vezes os professores se desesperam porque acreditam que as crianças que estão agressivas necessitam de atividades individualizadas, porém, estas precisam ser incluídas e o brincar, tanto individual como em grupo, facilita as relações interpessoais, já que acalma as crianças (Winnicott, 1975).

Para a faixa etária que envolve a educação infantil, atividades envolvendo barro, areia, massinha de modelar, desenho, água e tinta também são muito importantes, pois, as crianças têm 
liberdade para representar o que quiserem com esses materiais. Com relação aos jogos, sugeriu-se aos professores, por exemplo, que adaptassem as regras de brincadeiras como a "Dança da cadeira" e "Lenço que corra" para contemplar as necessidades das crianças com agressividade. Exemplo: como a criança com agressividade, em geral, já convive com muitas perdas em suas histórias pessoais, jogos que exploram o ganhar e o perder não são interessantes nesta fase inicial de trabalho com ela, pois incitam a externalização de conflitos emocionais já existentes, podendo gerar episódios agressivos durante a brincadeira. A nova versão da brincadeira "Dança da cadeira", sugerida ao grupo, consistia em manter o número de cadeiras similar ao número de crianças, de forma que nenhuma delas fosse excluída da brincadeira quando a música fosse interrompida. Já na brincadeira "Lenço que corra" a orientação foi a de que, quando uma criança fosse "queimada" pelo lenço, esta não sairia da brincadeira, mas, sim, a reiniciaria.

Conforme Moyles (2006), a partir do momento em que as crianças forem perdendo o interesse, significa que tudo o que poderiam retirar de benefício da atividade está esgotado, portanto, pode-se mudar as regras e incluir, progressivamente, a questão da perda nos jogos. Por fim, foram apresentadas brincadeiras de circuito, utilizando objetos como colchões, cadeiras, pneus e bolas, permitindo gasto de energia. Ressalta-se, no entanto, ainda conforme Moyles (2006), que as brincadeiras que envolvem apenas gasto de energia não trabalham aspectos emocionais, só amenizam a tensão da criança por algum tempo. Desta forma é relevante que o professor faça um planejamento, utilizando vários tipos de atividades.

Dentre as sugestões no que concerne à lida com a agressividade nas interações com a criança, foram apresentadas ao grupo as seguintes abordagens: 1- incentivar a criança que manifesta agressividade a se desculpar; 2- estimular o conserto de um objeto que ela eventualmente tenha quebrado, quando possível; 3- convidar a criança para auxiliar o professor nas atividades de sala, de alguma forma, para que se trabalhe com autoestima; 4- não destinar à criança, neste trabalho de auxílio ao professor, atividades que possam gerar conflitos com as outras, como por exemplo, verificar a realização de tarefas de casa; 5- valorizar os esforços e conquistas do aluno e, por fim, mas não menos importante, dialogar de forma simples com a criança diante de suas dificuldades relacionais, com respeito e autoridade, de forma que ela encontre a referência que precisa para se desenvolver. Após a exposição dessas sugestões, os professores se organizaram para a elaboração de projetos de trabalho, em grupos, se comprometendo a desenvolvê-los durante um mês.

Na quarta e última reunião os professores apresentaram o desenvolvimento dos referidos projetos com as crianças, expuseram materiais produzidos pelos alunos, portfólios e fotos, que foram enviadas pelo aplicativo WhatsApp à pesquisadora no decorrer do processo ${ }^{4}$. Ao término das exposições, os professores se mostraram satisfeitos e orgulhosos do trabalho realizado. As atividades desenvolvidas nas escolas foram diversas e estão sintetizadas na Tabela 3:

${ }^{4}$ Ocorreu por iniciativa dos professores. 
Tabela 3: Atividades desenvolvidas pelos professores em salas de aula

\section{GRUPOS DE PROFESSORES}

1

2

3

4

5

6

\section{ATIVIDADES DESENVOLVIDAS COM AS CRIANÇAS}

Escrita de carta/carimbo com as mãos/ execução de receita de bolo e pintura

Cantigas de roda/brincadeiras livres e em grupos

Fantoches/contação de história/massinha/brincadeiras com água

Circuito/Painel de sentimentos/"Lenço que corra"

"Mascote"/pintura e colagens em grupos

Teatro/"Dança da cadeira"/trabalho com texturas em grupos/músicas

Algumas das atividades foram ilustradas abaixo, utilizando-se imagens enviadas pelos professores por meio do WhatsApp:

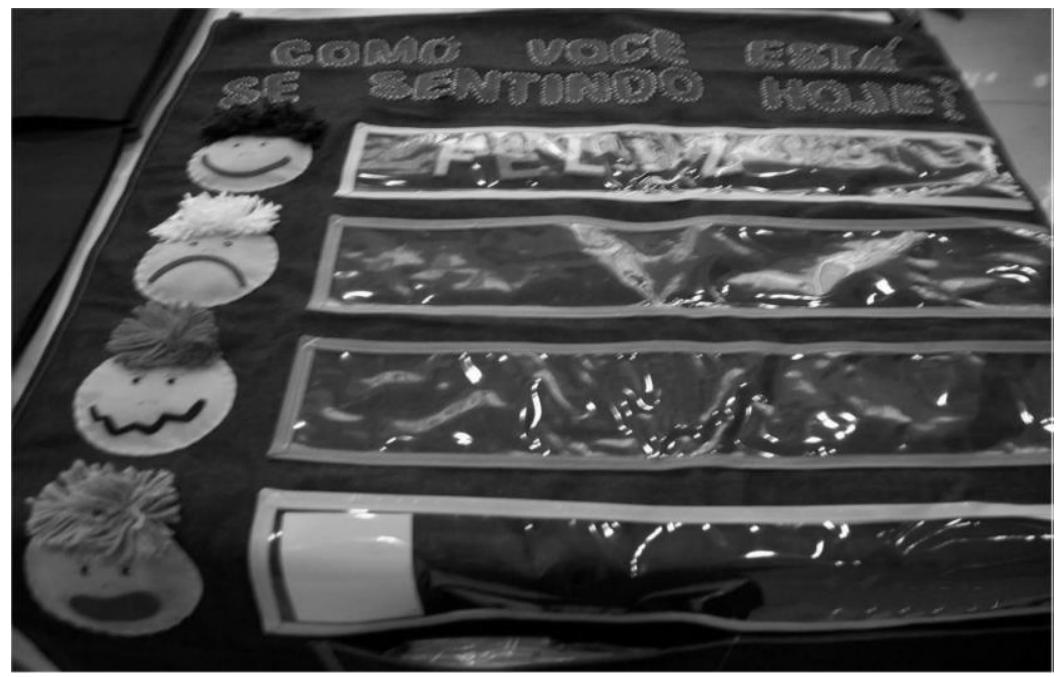

Figura 1. Painel de sentimentos. Fonte: Foto cedida pelo professor. 


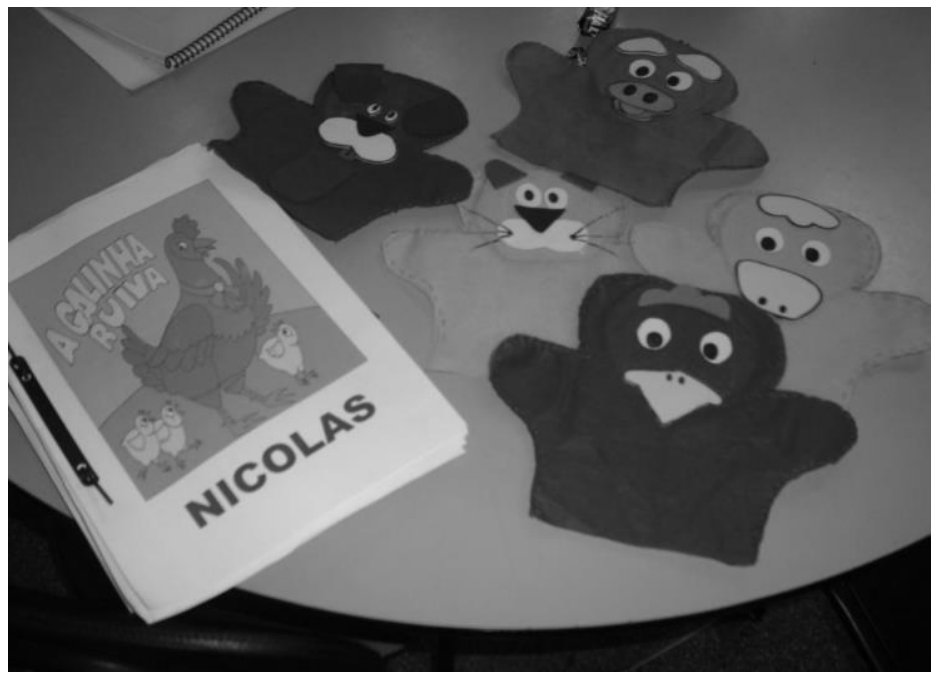

Figura 2. Fantoches produzidos para contação da história "A galinha ruiva ${ }^{5 " .}$ Fonte: Foto cedida pelo professor.

Conforme relatos dos professores o desenvolvimento dos projetos foi caracterizado por semanas 'intensas", no que se refere ao trabalho, participação e curiosidade das crianças durante as aulas. Ressaltaram que as crianças gostaram muito de participar de atividades como, por exemplo, a adoção de um mascote, que todos deveriam ajudar a cuidar em sistema de rodízio. As atividades de execução de receita de bolo, contação de histórias e teatro também foram marcantes para as crianças, que se envolveram, se divertiram e aprenderam. Os professores utilizaram fotos, anotações em diários de campo e um questionário para o registro das atividades nesta etapa da pesquisa.

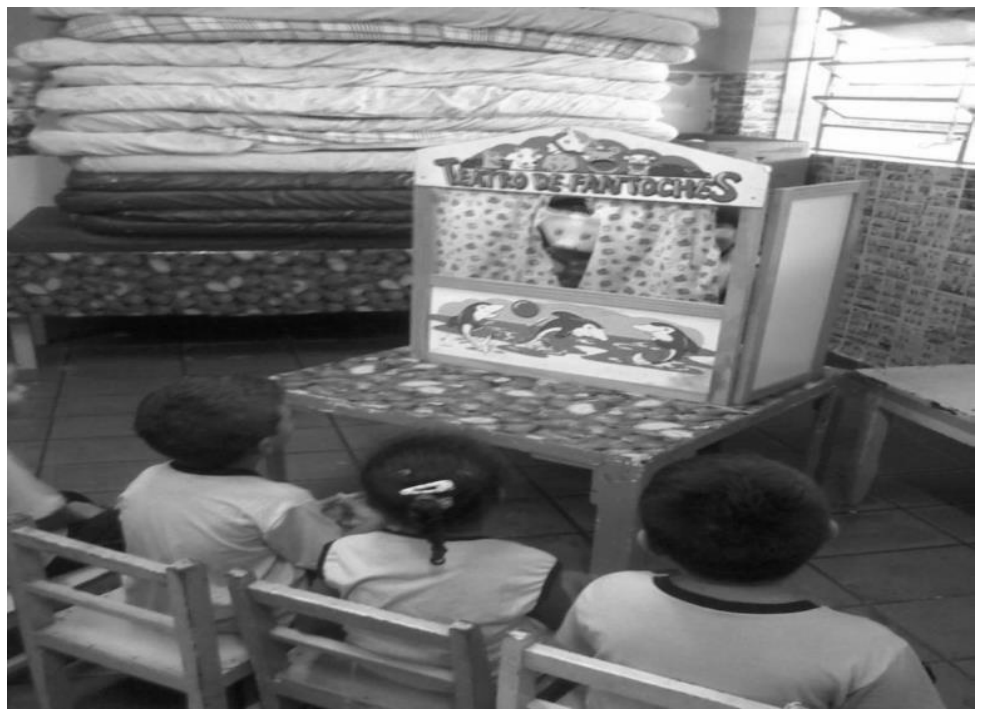

Figura 3. Apresentação de teatro. Fonte: Imagem cedida pelo professor.

\footnotetext{
${ }^{5} \mathrm{O}$ livro trata da história de uma galinha ruiva, que um dia percebe que o milho está maduro e pronto para ser colhido e virar um bom alimento. Diante disso, tem a ideia de fazer um bolo de milho e, para isso, busca ajuda entre os moradores da fazenda (animais).

${ }^{6}$ Termo utilizado pelos professores, para dizer que as atividades foram vigorosas, para além do comum.
}

HOLOS, Ano 36, v.6, e6260, 2020 
Ao final do processo os professores, por intermédio de questionários, avaliaram a pesquisa no que se refere aos impactos sobre as crianças e às suas práticas pedagógicas. Os resultados gerais podem ser observados na Tabela 4:

Tabela 4: Resultados alcançados com as crianças na percepção dos professores

\begin{tabular}{|c|c|c|}
\hline Respostas & Frequência & Porcentagem \\
\hline $\begin{array}{l}\text { Houve a participação de todas } \\
\text { as crianças da sala nas } \\
\text { atividades (crianças com } \\
\text { manifestações agressivas se } \\
\text { recusavam a participar das } \\
\text { atividades, em geral) }\end{array}$ & 25 & 37,3 \\
\hline $\begin{array}{l}\text { Houve uma rica interação entre } \\
\text { as crianças }\end{array}$ & 15 & 22,3 \\
\hline $\begin{array}{l}\text { Houve o desenvolvimento da } \\
\text { cooperação entre as crianças }\end{array}$ & 12 & 18 \\
\hline $\begin{array}{l}\text { Ocorreu uma inclusão social das } \\
\text { crianças com agressividade } \\
\text { (inicialmente essas crianças se } \\
\text { isolavam ou eram isoladas do } \\
\text { grupo) }\end{array}$ & 10 & 15 \\
\hline $\begin{array}{c}\text { Houve diminuição das } \\
\text { manifestações agressivas, de } \\
\text { todos os tipos (físicas e verbais) }\end{array}$ & 5 & 7,4 \\
\hline
\end{tabular}

Os relatos dos professores foram muito interessantes, pois, conseguiram comparar a qualidade da participação e interações entre as crianças nas atividades nos dias comuns de aula e no mês de desenvolvimento dos projetos. Todos os professores observaram uma maior participação e envolvimento das crianças durante a execução dos projetos, disseram que as crianças "ficaram encantadas". Dentre os comportamentos/atitudes observados nas crianças pelos professores, destacaram-se o respeito, gentileza, organização, trabalhe em equipe, cooperação e melhor interação entre as crianças que manifestavam agressividade e as demais. Ressaltaram, ainda, que o interesse levou as crianças a "se entenderem", de forma que houve poucos momentos de desavenças ou agressões, em comparação aos outros dias.

Com relação às atividades os professores apontaram que foi possível abordar temas relevantes, que constavam do planejamento escolar, ao mesmo tempo em que trabalharam as relações interpessoais e possibilitaram importantes experiências às crianças. Houve a percepção de que certas atividades, por despertarem mais a curiosidade das crianças, as levaram a uma maior HOLOS, Ano 36, v.6, e6260, 2020 
concentração. Alguns professores declararam estar receosos em voltar "às aulas normais" e o comportamento das crianças também se modificar. Neste momento da reunião foi oportuno à pesquisadora ponderar que o trabalho com agressividade precisa ser contínuo, para que haja um progressivo desenvolvimento social das crianças.

A partir das reações observadas nas crianças, os professores foram indagados se a participação na pesquisa os auxiliou efetivamente na construção de atividades que trabalhassem o desenvolvimento emocional/social das crianças. A resposta foi positiva para a maior parte dos participantes.

Tabela 5: Auxílio da pesquisa ao professor na elaboração de atividades que promovam o desenvolvimento emocional/social das crianças.

\begin{tabular}{c|c|c}
\hline Respostas & Frequência & Porcentagem \\
\hline Sim & 35 & $97.2 \%$ \\
Talvez & 1 & $2.8 \%$ \\
\hline
\end{tabular}

Por fim, questionados a respeito de como se sentiram com relação à participação na pesquisa, como protagonistas ${ }^{7}$, a satisfação dos professores foi nítida, como é possível observar nas respostas abaixo, obtidas nos questionários:

Tabela 6: Demonstrativo do nível de satisfação dos professores em relação à participação na pesquisa-ação.

\begin{tabular}{c|c|c}
\hline Respostas & Frequência & Porcentagem \\
\hline Muito satisfeito & 18 & $50 \%$ \\
Satisfeito & 16 & $44.4 \%$ \\
Indiferente & 2 & $5.6 \%$ \\
\hline
\end{tabular}

Em relação a esta questão, assim se posicionou a Professora Gabriella ${ }^{8}$, que afirmou estar satisfeita com o resultado obtido:

Estou extremamente satisfeita, o projeto foi importantíssimo para trabalhar o comportamento das crianças, a solidariedade entre eles e o companheirismo nas atividades mais complicadas, eu adorei! Achei criativo, de fácil aplicação, e consegui atingir meu objetivo de unir as crianças e mantê-las atentas as atividades. Além disso, o projeto proporcionou a formação continuada, nos ensinando a melhor forma possível de trabalhar com crianças agressivas.

\footnotetext{
${ }^{7}$ A participação como protagonista é tida como uma das características da pesquisa-ação, em que os sujeitos trabalham ativamente para a solução de um problema.

${ }^{8}$ Trecho extraído do questionário de avaliação da pesquisa.
}

HOLOS, Ano 36, v.6, e6260, 2020 
Abaixo, encontram-se as impressões de Adrielli ${ }^{9}$, discente do curso de Pedagogia que auxiliou na realização da pesquisa:

Após a verificação das atividades aplicadas pelos professores, a forma como expunham e falavam sobre o trabalho que haviam desenvolvido e a satisfação presente em seus semblantes, pude perceber quão maravilhosa foi a experiência de vincular teoria e prática e trabalhar em parceria com as escolas nesta pesquisa-ação. Ainda maior foi a minha satisfação em auxiliar os professores em sua formação continuada e contribuir indiretamente para que realizassem um trabalho de constante ajuda à criança que demonstra agressividade no ambiente escolar, principal objetivo do projeto. Além disso, pude perceber a motivação dos professores, por meio das atividades aplicadas, demonstrando que só faltava alguém que pudesse trabalhar junto com eles. Sem dúvida o grande desafio vencido por todos nós foi de trabalhar com atividades pedagógicas brincando, que, ao mesmo tempo em que ensinam, divertem e auxiliam a criança em seu desenvolvimento emocional.

Considerando todas as etapas da experiência é importante ressaltar o empenho e a dedicação dos professores, tanto no desenvolvimento como na avaliação da pesquisa. A atuação deles em muito contribuiu para a construção de conhecimentos com relação ao tema e avançar na intenção de produzir material que auxilie os professores em sala de aula. Por meio desta pesquisa verificou-se que as crianças necessitam de orientação e direcionamento para atividades pedagógicas específicas, para que se desenvolvam emocional e socialmente e encontrem na escola um espaço acolhedor e adequado às suas necessidades de crescimento, tal como preconiza Winnicott (1982).

\section{CONSIDERAÇÕES FINAIS}

A pesquisa permitiu abrir espaço para que os sentimentos e concepções dos professores em relação às crianças que manifestam muita agressividade fossem externalizados e trabalhados, de forma que o grupo pode elaborar, aplicar e avaliar práticas alternativas com essas crianças. A pesquisa trouxe a realidade das crianças com agressividade aos olhos dos professores, indicando possibilidades de trabalho com o desenvolvimento emocional e social destas por meio de atividades lúdicas e abordagens específicas, em termos de interações professor-aluno, fazendo da escola um ambiente tranquilo e propício para o desenvolvimento.

Os professores, conforme se verifica em Castro (2008), ficam muito desgastados quando expostos a crianças que manifestam muita agressividade. Geralmente eles entram em esgotamento físico e emocional, desistem das crianças ou, então, criam certa frieza nos relacionamentos como forma de defesa, em razão de seu próprio sofrimento. Em sua pesquisa Castro (2008) indaga: Quem cuida desses professores? Uma forma de cuidarmos deles estaria em estabelecer parcerias e realizar pesquisas coletivas como esta, oferecendo atenção a seus pedidos de auxílio antes que cheguem ao limite de sua saúde.

${ }^{9}$ Bolsista CNPq; relato extraído do questionário de avaliação da pesquisa. 
Pelos resultados obtidos fica claro que a parceria entre universidade e escola gera muitos frutos e que os professores estão disponíveis a um trabalho como este, o que nos motiva à continuidade da pesquisa, tendo em conta a necessidade de ampliação do número de professores participantes para que possa ser delineada uma prática ainda mais detalhada - em termos de planejamento e abordagens interacionais com as crianças - para os professores. O trabalho teórico a respeito da agressividade também se mostrou extremamente necessário, o que indica a necessidade de que os cursos de formação inicial e continuada, bem como os gestores escolares, se atentem a esta demanda. A presença de psicopedagogos e/ou psicólogos escolares que possam orientar aos professores e pais também é de fundamental importância, pois, os resultados alcançados nesta pesquisa abrangem somente aquelas crianças cuja situação ainda não exige um acompanhamento especializado.

Novas pesquisas que contribuiriam à produção na área, como ficou claro no decorrer deste trabalho, seriam aquelas voltadas à investigação e construção de práticas que auxiliem o professor no trabalho com crianças com muita agressividade, incluindo fortemente as abordagens na relação professor-aluno. A maior dificuldade docente reside em auxiliar as crianças no gerenciamento de suas emoções, um trabalho específico neste sentido seria muito especial.

\section{REFERÊNCIAS}

ABERASTURY, A. (1982). A criança e seus jogos (2a ed.). Porto Alegre: Artmed.

BARDIN, A. (2006). Análise de conteúdo. Lisboa: Edições 70.

CASTRO, R. E. (2008). Eles cuidam de crianças. Quem cuida deles? O sofrimento psíquico do professor na relação com a criança considerada agressiva. Dissertação de mestrado, Universidade de São Paulo, São Paulo, SP, Brasil.

COSTA, M. V. (1996). Introdução: novos olhares na pesquisa em educação. In: . Caminhos investigativos: novos olhares na pesquisa em educação (Cap. 1, pp. 7-17). Porto Alegre: Mediação.

MOYLES, J. R. (2006). A excelência do brincar: a importância da brincadeira na transição entre a educação infantil e anos iniciais. Porto Alegre: Artmed.

PERVOVA, I. (1999). Aggression and violence on the move in russian schoolchildren. Preventing School failure, 1(44), 28-31.

THIOLLENT, M. (2005). Metodologia da Pesquisa-ação (14a ed.). São Paulo: Cortez.

WINNICOTT, D. W. (1975). O brincar \& a realidade. Rio de Janeiro: Imago.

WINNICOTT, D.W. (1982). A criança e o seu mundo (6a ed.). Rio de Janeiro: Livros Técnicos e Científicos. 
WINNICOTT, D. W. (1992). Natureza humana. Rio de Janeiro: Imago.

WINNICOTT, D.W. (2000). Da pediatria à psicanálise: obras escolhidas. Rio de Janeiro: Imago.

WINNICOTT, D.W. (2005). Privação e delinqüência (4a ed.). São Paulo: Martins Fontes.

\section{COMO CITAR ESTE ARTIGO:}

Wiezzel , A. C. S. (2020). Agressividade e escola: projeto de intervenção protagonizado por professores. Holos, 36(6), 1-19.

\section{SOBRE OS AUTORES}

\section{A. C. S. WIEZZEL}

Graduada em Pedagogia. Mestre e Doutora em Educação pela Universidade Estadual Paulista Julio de Mesquista Filho - Unesp, respectivamente pelos campus de Presidente Prudente e Marília-SP. Docente da Pós-graduação e do Departamento de Educação da Universidade Estadual Paulista, no campus de Presidente Prudente-SP, na área de Psicologia da Educação. E-mail: andreia.wiezzel@unesp.br.

ORCID ID: http://orcid.org/0000-0003-4592-5421

Editor(a) Responsável: Francinaide de Lima Silva Nascimento

Pareceristas Ad Hoc: DAVID AZEVEDO E AMAILSON BARROS

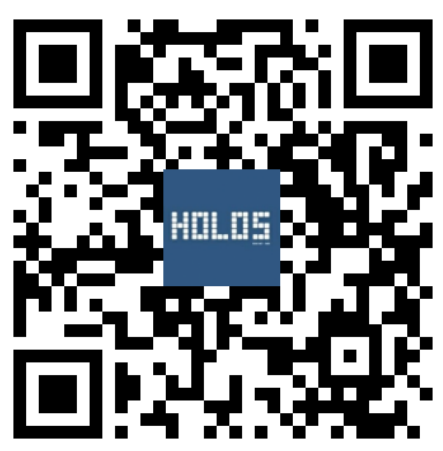

